\title{
Transverse myelitis complicating Mycoplasma pneumoniae infection
}

\author{
GeOFFrey NichOLSON \\ B.Sc., M.R.C.P.
}

\author{
Dudley Road Hospital, Birmingham
}

\begin{abstract}
Summary
A 23-year-old man developed transverse myelitis following an infection with Mycoplasma pneumoniae. Neurological complications following infection with this organism are uncommon but the prognosis appears to be good.
\end{abstract}

\section{Case report}

A 23-year-old welder was admitted with a 2-week history of dry cough, headache, anorexia and increasing dyspnoea. Five days before admission he had developed low back pain, which was worse on coughing, together with weakness and paraesthesiae of the legs and arms, which progressed over the next few days so that he became too weak to stand. $\mathrm{He}$ had been vomiting for 2 days before admission and had become incontinent of urine.

On examination he was dehydrated but apyrexial. His pulse was $110 / \mathrm{min}$, blood pressure $110 / 90 \mathrm{mmHg}$, respiratory rate $22 / \mathrm{min}$. He had a flaccid paresis affecting the legs and arms up to the spinal level of C6. His biceps and ankle jerks were present but all other reflexes were absent. Sensation was absent below a clear demarcation level at T2. There was no abnormality of the cranial nerves or fundi. He had retention of urine and gaseous distension of the bowel.

Investigations revealed evidence of haemoconcentration, with a haemoglobin of $18 \mathrm{~g} / \mathrm{dl}$ and a blood urea of $17 \mathrm{mmol} / \mathrm{l}$. The white cell count was $20 \times 10^{\%} / 1$ with a polymorphonuclear leucocytosis. A chest radiograph showed patchy infective consolidation affecting the left lower zone. The Mycoplasma pneumoniae complement fixation test was positive at a titre of $1: 2000$. A lumbar puncture showed normal cerebrospinal fluid (CSF) pressure and dynamics and the CSF contained sugar $4.0 \mathrm{mmol} / \mathrm{l}$, protein $0.65 \mathrm{~g} / \mathrm{l}$ and $10 \times 10^{6}$ lymphocytes $/ \mathrm{l}$. A myelogram revealed no abnormality. The arterial $\mathrm{Po}_{2}$ was 6.4 $\mathrm{kPa}, \mathrm{PCO}_{2}$ was $5.5 \mathrm{kPa}$; the tidal volume was $400 \mathrm{ml}$ with a vital capacity of $900 \mathrm{ml}$.

Despite physiotherapy, he was unable to raise sputum satisfactorily and a tracheostomy was required. He was given added oxygen, antibiotics, steroids and was fed intravenously. He improved steadily and 2 weeks after admission he was able to take oral feeds and maintain adequate ventilation without a tracheostomy. Sensation and motor function returned during rehabilitation at a spinal injuries centre; after 3 months he could walk with the aid of a stick and he resumed normal work after 6 months. His residual complaints were numbness over the outer aspect of the left thigh, occasional urinary incontinence, and impotence. By 12 months, the Mycoplasma complement fixation titre had fallen to $1: 32$.

\section{Discussion}

The diagnosis of transverse myelitis was made on the basis of the clinical features, lumbar puncture findings and normal myelogram.

Neurological complications of $M$. pneumoniae infection are uncommon but include meningitis meningoencephalitis, polyneuropathy, cranial nerve palsies, and cerebellar ataxia (Hodges, Fass and Saslaw, 1972; Murray et al., 1975; Jachuck et al., 1975). Earlier series (Yesnick, 1956) contained reports of transverse myelitis complicating primary atypical pneumonia, but in these cases the diagnosis was based on the cold agglutinin titre which, although often raised in $M$. pneumoniae infections, is relatively non-specific. Transverse myelitis occurring as a complication of a serologically proved $M$. pneumoniae infection has been reported previously (Nagaswami et al., 1973), but is rare.

Transverse myelitis of unknown cause has a variable prognosis, with the paraplegia persisting in one-third of cases (Lipton and Teasdall, 1973). The patient made an almost complete recovery despite a marked initial neurological deficit, and this seems to be a feature of other neurological complications of M. pneumoniae infection (Hodges et al., 1972). An aggressive therapeutic approach in such cases thus seems justified.

\section{Acknowledgments}

I would like to thank Dr J. F. Riordan (Consultant Physician, Dudley Road Hospital) and Dr H. W. Francis Jones (Consultant Physician, Institute of Orthopaedics, Oswestry) for permission to report this case, and Mrs Vivian Allen for secretarial assistance. 


\section{References}

Hodges, G.R., Fass, R.J. \& Saslaw, S. (1972) Central nervous system disease associated with Mycoplasma pneumoniae infection. Archives of Internal Medicine, 130, 277.

Jachuck, S.J., Gardner-Thorpe, C., Clark, F. \& Foster, J.B. (1975) A brainstem syndrome associated with Mycoplasma pneumoniae infection-a report of two cases. Postgraduate Medical Journal, 51, 475.

Lipton, H.L. \& TEasdall, R.D. (1973) Acute transverse myelopathy in adults-a follow-up study. Archives of Neurology, 28, 252.
Murray, H.W., Masur, H., Senterfit, L.B. \& Roberts, R.B. (1975) The protean manifestations of Mycoplasma pneumoniae infection in adults. American Journal of Medicine, 58, 229.

Nagaswami, S., Kepes, J., Foster, D.B. \& Twemlow, S.W. (1973) Necrotizing myelitis: a clinico-pathological report of two cases associated with Diplococcus pneumoniae and Mycoplasma pneumoniae infections. Transactions of the American Neurological Association, 98, 290.

YeSNICK, L. (1956) Central nervous system complications of primary atypical pneumonia. Archives of Internal Medicine, 97, 93.

\section{Chlorpropamide-induced thrombocytopenia}

\author{
D. J. Cunliffe \\ F.I.M.L.S.
}

\author{
D. W. Gorst \\ M.A., M.R.C.P.
}

\author{
H. M. PALMer \\ M.A., M.R.C.P.
}

\begin{abstract}
Summary
Thrombocytopenia is a rare complication of chlorpropamide therapy. An immunological mechanism is generally held responsible, but has never previously been proved. In the present case the existence of such a mechanism has been established.
\end{abstract}

\section{Case report}

The patient was an obese, 64-year-old Asian woman with newly-diagnosed diabetes. She was treated with a combination of metformin $850 \mathrm{mg}$ b.d., chlorpropamide $500 \mathrm{mg}$ daily and dietary carbohydrate restriction. Two weeks after treatment was started she developed haemorrhagic bullae in her mouth and extensive purpura and bruising on her limbs and trunk. She had taken no drugs other than metformin and chlorpropamide.

The platelet count was less than $10 \times 10^{\circ} / 1$, haemoglobin $14.0 \mathrm{~g} / \mathrm{dl}$, white cell count $4.2 \times 10^{\circ} / 1$ and the blood film showed normal red cells. Tests for faecal occult blood were positive and there was microscopic haematuria. Serum fibrin degeneration products were not detected and the bone marrow was morphologically normal.

Oral hypoglycaemic therapy was discontinued and prednisolone begun. The platelet count steadily increased (see Fig. 1) and prednisolone was withdrawn after 14 days. At this stage, metformin was restarted and continued for $\mathbf{8}$ days without adversely affecting the platelet count which ultimately rose to $190 \times 10^{9} / 1$.

\section{Methods}

Blood samples were taken from the patient 1 week and 3 weeks after the onset of purpura. A further sample was obtained immediately before discharge from hospital some 4 weeks after purpura developed.

The samples were allowed to clot and the sera separated and stored at $-20^{\circ} \mathrm{C}$. Samples from three normal donors were collected and processed in a similar manner. Each serum, test and control, with and without chlorpropamide, was tested for evidence of drug-dependent platelet antibodies.

\section{Inhibition of clot retraction}

The delayed test of Shulman et al. (1964) utilizing normal platelet-rich plasma and incorporating magnesium chloride was modified by including an aliquot of drug solution in the reaction mixture. An equivalent volume of distilled water replaced the drug in the control series.

\section{Anti-human globulin (AHG) consumption test}

The test was performed according to Steffen (1960) modified in this laboratory in order to assess chlorpropamide involvement in a platelet 'anti-platelet' system. 